\title{
The Effect of Minimally Invasive Surfactant Therapy on Diaphragmatic Activity
}

\author{
Cornelia G. de Waal ${ }^{\mathrm{a}}$ Gerard J. Hutten ${ }^{\mathrm{a}}$ Frans H. de Jongh ${ }^{\mathrm{a}}$ \\ Anton H. van Kaam ${ }^{a, b}$ \\ ${ }^{a}$ Department of Neonatology, Emma Children's Hospital, Academic Medical Center, Amsterdam, The Netherlands; \\ bepartment of Neonatology, VU University Medical Center, Amsterdam, The Netherlands
}

\section{Keywords}

Electromyography of the diaphragm · Preterm infants .

Respiratory distress syndrome $\cdot$ Surfactant

\begin{abstract}
Background: Minimally invasive surfactant therapy (MIST) is increasingly used to treat preterm infants with respiratory distress syndrome (RDS). However, the effect of MIST on breathing effort is poorly studied. Objectives: To describe the effect of MIST on neural breathing effort assessed with transcutaneous electromyography of the diaphragm (dEMG) in preterm infants with RDS. Methods: Preterm infants with a gestational age $<37$ weeks treated with MIST for RDS were included. dEMG measurements were done from $15 \mathrm{~min}$ before to $1 \mathrm{~h}$ after MIST. The percentage change in dEMG activity after MIST and the clinical response were analyzed. Results: Twenty preterm infants (mean gestational age 29.3 [SD 2.1] weeks; mean birth weight 1,230 [SD 391] g) were included. Seventeen infants did complete the 1-h measurement. Eleven (65\%) infants had a decrease in their peak dEMG activity (median change $-11.8 \%$ [IQR -26.8 to $5.8, p=0.08$ ]) $1 \mathrm{~h}$ after MIST. Tonic $\mathrm{dEMG}_{\mathrm{dEM}}$ activity decreased in $12(71 \%)$ infants, with a median reduction of $6.3 \%$ (IQR -29.2 to $9.0, p=$
\end{abstract}

\section{KARGER}

E-Mail karger@karger.com www.karger.com/neo
(C) 2018 The Author(s) Published by S. Karger AG, Basel

Karger 0 pen access

This article is licensed under the Creative Commons AttributionNonCommercial-NoDerivatives 4.0 International License (CC BYNC-ND) (http://www.karger.com/Services/OpenAccessLicense). Usage and distribution for commercial purposes as well as any distribution of modified material requires written permission.
0.07). $\mathrm{FiO}_{2}$ showed a rapid decrease following MIST (before, 0.47 [IQR 0.38-0.84]; $1 \mathrm{~h}$ after, 0.25 [IQR 0.21-0.30], $p<0.001$ ). Conclusion: In addition to improved oxygenation, MIST results in a decrease in neural breathing effort measured by dEMG activity in the majority of preterm infants with RDS.

(c) 2018 The Author(s)

Published by S. Karger AG, Basel

\section{Introduction}

Neonatal respiratory distress syndrome (RDS) is common in preterm infants and the main cause of respiratory failure in the first days of life [1]. RDS is characterized by surfactant deficiency leading to atelectasis and a low endexpiratory lung volume (EELV) [2]. Furthermore, compliance of the respiratory system is decreased while airway resistance is increased [2]. This will result in impaired gas exchange and increased work of breathing.

The treatment of RDS consists of respiratory support and exogenous surfactant administration. This surfactant administration improves pulmonary function and, more importantly, results in less neonatal mortality and morbidity [3]. Traditionally, surfactant is administered via an endotracheal tube. However, to prevent adverse effects of 
intubation and mechanical ventilation, surfactant is increasingly administered while infants are breathing spontaneously with nasal continuous positive airway pressure (nCPAP) support. During this so-called minimally invasive surfactant therapy (MIST) procedure, surfactant is administered via a small catheter inserted through the vocal cords into the trachea [4-6].

In contrast to endotracheal surfactant treatment, the effect of MIST on pulmonary function has been poorly studied. Although it has been established that MIST results in a rapid increase in EELV, thereby improving oxygenation [7], the effect on breathing effort is unknown.

Recently, transcutaneous electromyography of the diaphragm (dEMG) has been introduced as a noninvasive easy-to-use bedside monitoring tool in neonatal intensive care [8]. dEMG measures the electrical activity of the diaphragm, the main respiratory muscle in preterm infants. This electrical activity of the diaphragm is considered a noninvasive measure of neural drive and breathing effort [9].

The primary aim of this study is to describe the effect of exogenous surfactant administration via the MIST procedure on neural breathing effort assessed by measuring the electrical activity of the diaphragm. We hypothesize that the neural breathing effort will decrease after MIST.

\section{Methods}

\section{Study Population}

This prospective observational cohort study was conducted in the neonatal intensive care unit (NICU) of the Academic Medical Center (Amsterdam, The Netherlands). Infants born between 26 and 37 weeks of gestation were eligible if diagnosed with RDS and treated with a first dose of exogenous surfactant via the MIST procedure. According to our department protocol, infants were candidates for MIST if they received nCPAP $\geq 6 \mathrm{cmH}_{2} \mathrm{O}$ with a $\mathrm{FiO}_{2}$ $>0.30$ and had an adequate respiratory drive and a postnatal age $<72 \mathrm{~h}$. Based on these same criteria, infants could be treated with a subsequent dose of surfactant given either via MIST or via endotracheal intubation. Infants with major congenital anomalies of the chest or abdomen were excluded. The study protocol was approved by the Medical Ethics Committee of the Academic Medical Center Amsterdam and informed consent was obtained from both parents before the start of this study.

\section{MIST Procedure}

The MIST procedure was based on the technique described by Göpel et al. [4]. Briefly, infants were placed in supine position and the larynx was visualized by laryngoscopy while receiving nCPAP. Local anesthesia was induced with lidocaine spray, after which a 3.5 - or 5 -french catheter was placed $1-2 \mathrm{~cm}$ below the vocal cords using a Magill forceps. The surfactant (Curosurf $80 \mathrm{mg} / \mathrm{mL}$; Chiesi Pharmaceuticals BV, Amsterdam, The Netherlands) was dosed by vial and administered slowly over 1-3 min.

Diaphragmatic Activity after Surfactant

Therapy

\section{Study Procedure}

The dEMG measurement was started 15 min before the MIST procedure and continued up to $1 \mathrm{~h}$ after surfactant administration. Three skin electrodes (disposable Kendall H59P electrodes; Covidien, Mansfield, MA, USA), i.e., 2 in the left and right nipple line at the costo-abdominal margin and 1 ground electrode on the sternum, were used. The electrodes were connected to a portable 16-channel physiological amplifier (Dipha-16; Demcon, Son, The Netherlands) which was wirelessly connected to a bedside computer. The raw, monopolar EMG signals were digitally transformed to a bipolar EMG signal and high-pass filtered in Polybench (Applied Biosignals, Weener, Germany). The electrical activity of the heart was removed from the EMG signal and the resulting gated EMG signal was filled with a running average as described by O'Brien et al. [10]. This averaged dEMG signal was post processed and used for the data analyses. More information on the technical aspects of the signal processing are provided elsewhere $[10,11]$.

Standard monitoring of the heart rate and respiratory rate with chest impedance and oxygen saturation with pulse oximetry were continued during the measurement.

\section{Data Collection}

The following characteristics were collected when infants were included in this study: gestational age, birth weight, Apgar score, administration of antenatal steroids, mode of delivery, and postnatal age at MIST (in h). The settings of the respiratory support, including the $\mathrm{FiO}_{2}$, were closely monitored during the measurement. During 3 days following the first MIST, data on changes in respiratory support and the need for additional surfactant doses were collected.

Stable 30-s recordings without movement or technical artifacts were selected at baseline (time $=-5 \mathrm{~min}$ ) and $1 \mathrm{~h}$ after MIST (time $=+60 \mathrm{~min})$. For each individual breath in these selected recordings, the following $\mathrm{dEMG}$ parameters were assessed: peak $_{\text {dEMG }}$ activity $(\mu \mathrm{V})$, tonic dEMG $_{\text {activity }}(\mu \mathrm{V})$, and ampli-

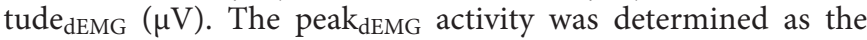
highest point in the signal, the tonic dEMG $_{\text {activity was determined }}$ as the lowest point in the signal, and the amplitude dEMG $_{\text {was }} \mathrm{cal}-$ culated as the difference between the highest ( peak $_{\mathrm{dEMG}}$ ) and lowest (tonic $\mathrm{dEMG}_{\mathrm{dE}}$ ) points. These dEMG parameters were averaged over all breaths detected in the selected $30 \mathrm{~s}$ of recording for each individual infant. The percentage change $(\Delta \%)$ in peak dEMG $_{\text {activ- }}$ ity, tonic $\mathrm{dEMG}_{\mathrm{dEM}}$ activity, and amplitude $\mathrm{dEMG}_{\mathrm{A}}$ was calculated compared to baseline. The inspiratory time $\left(\mathrm{Ti}_{\mathrm{dEMG}}, \mathrm{s}\right)$, the expiratory time $\left(\mathrm{Te}_{\mathrm{dEMG}}, \mathrm{s}\right)$, the respiratory rate (breaths per min), and the heart rate (beats per min) were extracted from the dEMG signal as well. To be able to describe the change over time within the 1-h measurement period, we also assessed these dEMG parameters $5 \mathrm{~min}($ time $=+5 \mathrm{~min})$ and $30 \mathrm{~min}($ time $=+30 \mathrm{~min})$ after MIST.

\section{Statistical Analysis}

SPSS version 24.0 (IBM, Armonk, NY, USA) and GraphPad Prism 5.0 (GraphPad Software, San Diego, CA, USA) were used for the statistical analysis. Data were expressed as mean \pm SD or median (IQR), depending on their distribution.

The overall changes in diaphragmatic activity and clinical parameters were compared before and $1 \mathrm{~h}$ after MIST using a Wilcoxon signed-rank test. Based on the change in diaphragmatic activity $1 \mathrm{~h}$ after MIST compared to baseline, the infants were di- 
Table 1. Baseline characteristics of the study population

\begin{tabular}{lc}
\hline Characteristic & Value \\
\hline Gestational age at birth, weeks & $29.3 \pm 2.1$ \\
Birth weight, g & $1,230 \pm 391$ \\
Male & $11(55 \%)$ \\
Complete course of antenal steroids & $6(30 \%)$ \\
Caesarean section & $11(55 \%)$ \\
Apgar score at 5 min & $8(7-9)$ \\
Postnatal age at measurement, h & $5(4-14)$ \\
nCPAP level, cm $\mathrm{Cm}_{2} \mathrm{O}$ & $6(6-7)$ \\
$\mathrm{FiO}_{2}$ & $0.47(0.38-0.84)$ \\
\hline
\end{tabular}

The total number of patients is 20 . Values are presented as mean $\pm \mathrm{SD}$, number (\%), or median (IQR). nCPAP, nasal continuous positive airway pressure.

vided into a group showing a decrease in diaphragmatic activity and a group showing an increase in diaphragmatic activity. Patient and clinical characteristics were compared between these 2 groups. For normally distributed numerical data an unpaired $t$ test was employed, and for non-normally distributed numerical data a Mann-Whitney U test was used. A $\chi^{2}$ test was used for categorical data. $p<0.05$ was considered statistically significant.

\section{Results}

\section{Study Population}

Twenty-one preterm infants were included in this study. One infant did not receive MIST because it was technically not possible to insert the catheter in this extremely low birth weight infant weighing $465 \mathrm{~g}$. This infant was therefore not included in the analysis. The basic characteristics of the remaining 20 infants are shown in Table 1 . The median surfactant dose was $200 \mathrm{mg} / \mathrm{kg}$ (IQR 159-210). In 3 infants the measurement was stopped early due to respiratory failure and the need for endotracheal intubation and ventilation. Nine (45\%) infants needed a subsequent dose of surfactant after the first MIST procedure and 7 (35\%) infants needed mechanical ventilation in the first $72 \mathrm{~h}$ after birth.

\section{The Effect of MIST on Diaphragmatic Activity}

One hour after MIST, 11 (65\%) infants showed a decrease in peak $\mathrm{dEMG}_{\mathrm{d}}$ activity and 12 (71\%) infants showed a decrease in tonic ${ }_{\mathrm{dEMG}}$ activity. The median percentage change in peak $\mathrm{dEMG}_{\mathrm{dEM}}$ activity and tonic $\mathrm{dEMG}_{\mathrm{dEM}}$ activity was $-11.8 \%$ (IQR -26.8 to $5.8, p=0.08$ ) and $-6.3 \%$ (IQR -29.2 to $9.0, p=0.07$ ), respectively, $1 \mathrm{~h}$ after MIST (Table 2 ).

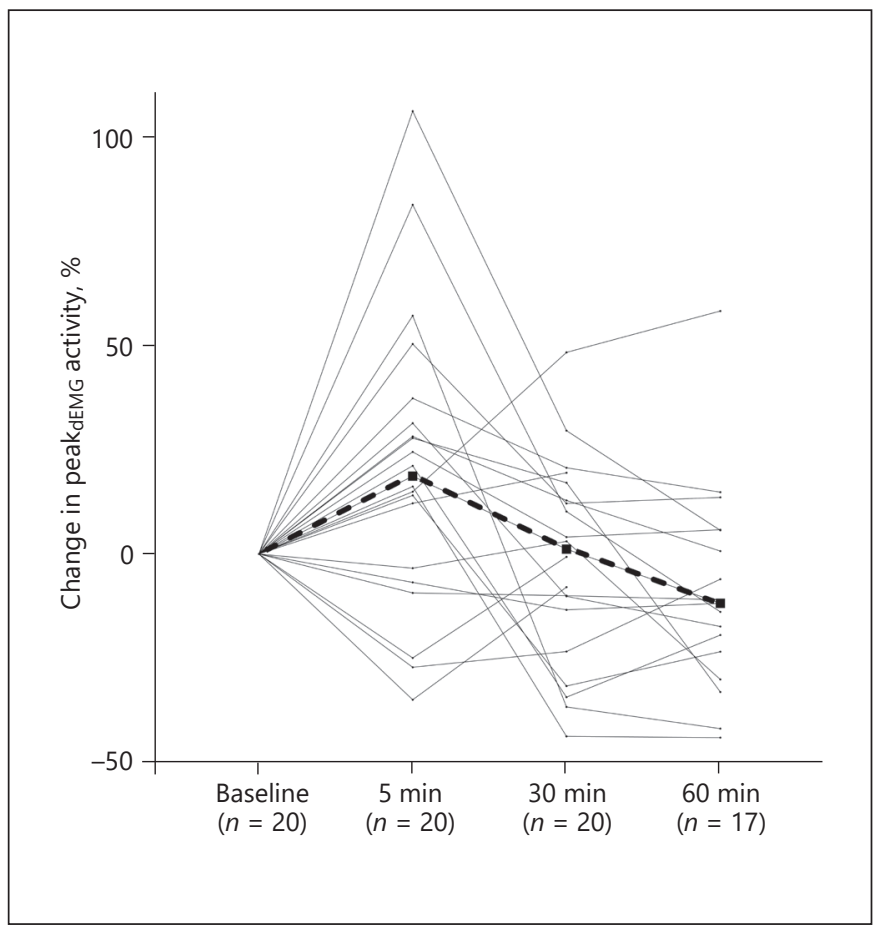

Fig. 1. Percentage change in peak $\mathrm{dEMG}_{\mathrm{G}}$ activity over time compared to baseline. Every line represents an infant. The bold, dashed line represents the median change over time in the first hour after minimally invasive surfactant therapy. dEMG, electromyography of the diaphragm.

The percentage change in peak $\mathrm{dEMG}_{\mathrm{d}}$ activity over time per infant is shown in Figure 1. The peak $\mathrm{dEMG}_{\mathrm{dE}}$ activity tended to increase in the first $5 \mathrm{~min}$ after MIST, followed by a gradual decrease at time $=+30$ and time $=+60 \mathrm{~min}$ in the majority of the infants. A similar pattern was seen for tonic dEMG $_{\text {activity and the amplitude }}$ dEMG $_{\text {(Table 2). }}$.

Comparison of the group of infants who showed a

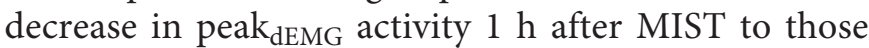
who showed an increase revealed no significant differences in gestational age, birth weight, postnatal age at measurement, baseline $\mathrm{FiO}_{2}$, the change in $\mathrm{FiO}_{2} 1 \mathrm{~h}$ after MIST, or the need for an additional dose of surfactant (Table 3).

\section{The Effect of MIST on Clinical Parameters}

$\mathrm{FiO}_{2}$ showed a significant, rapid, and persistent decrease following MIST (baseline, 0.47 [IQR 0.38-0.84]; +5 min, 0.30 [IQR 0.28-0.55]; and $+60 \mathrm{~min}, 0.25$ [IQR $0.21-0.30], p<0.001)$. $\mathrm{Ti}_{\mathrm{dEMG}}, \mathrm{Te}_{\mathrm{dEMG}}$, respiratory rate, and heart rate did not change in the first hour after MIST (Table 2). 
Table 2. Change in dEMG-derived parameters and clinical parameters over time

\begin{tabular}{|c|c|c|c|c|}
\hline \multicolumn{5}{|l|}{ dEMG-derived parameters } \\
\hline$\Delta$ tonic $_{\mathrm{dEMG}}$ activity, $\%$ & $0.0(0.0$ to 0.0$)$ & $2.5(-10.0$ to 34.2$)$ & $1.7(-25.4$ to 9.4$)$ & $-6.3(-29.2$ to 9.0$)$ \\
\hline$\Delta$ amplitude $_{\mathrm{dEMG}}, \%$ & $0.0(0.0$ to 0.0$)$ & $34.3(-4.0$ to 49.8$)$ & $1.2(-16.1$ to 22.5$)$ & $-5.8(-21.0$ to 7.4$)$ \\
\hline \multicolumn{5}{|l|}{ Absolute parameters } \\
\hline Respiratory rate, breaths/min & $65(53$ to 73$)$ & $58(53$ to 71$)$ & $65(56$ to 77$)$ & $69(62$ to 77$)$ \\
\hline Heart rate, beats/min & $144(138$ to 158$)$ & $150(137$ to 160$)$ & $147(132$ to 157$)$ & $144(132$ to 157$)$ \\
\hline $\mathrm{FiO}_{2}$ & $0.47(0.38$ to 0.84$)$ & $0.30(0.28$ to 0.55$)$ & $0.27(0.21$ to 0.38$)$ & $0.25(0.21$ to 0.30$)$ \\
\hline
\end{tabular}

dEMG-derived parameters are presented as a percentage change compared to baseline. Data are expressed as median (IQR). dEMG, electromyography of the diaphragm; $\mathrm{Ti}_{\mathrm{dEMG}}$, inspiratory time; $\mathrm{Te}_{\mathrm{dEMG}}$, expiratory time.

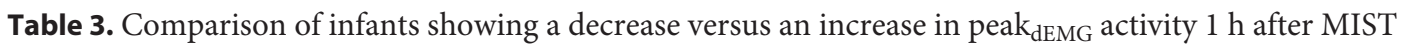

\begin{tabular}{lccc}
\hline & Decrease $(n=11)$ & Increase $(n=6)$ & $p$ \\
\hline Gestational age, weeks & $29.8 \pm 2.1$ & $29.4 \pm 2.5$ & 0.75 \\
Birth weight, $g$ & $1,328 \pm 421$ & $1,079 \pm 414$ & 0.26 \\
Postnatal age at measurement, $\mathrm{h}$ & $6(5$ to 20$)$ & $9(4$ to 16$)$ & 0.59 \\
Cases in which surfactant was needed a second time & $4(36.4 \%)$ & $2(33.3 \%)$ & 0.90 \\
$\mathrm{Baseline}^{\mathrm{FiO}}$ & $0.46(0.31$ to 0.80$)$ & $0.45(0.40$ to 0.59$)$ & 0.81 \\
$\Delta \mathrm{FiO}_{2}$ at 60 min compared to baseline, \% & $-46(-60$ to -30$)$ & $-49(-57$ to -35$)$ & 0.88 \\
\hline
\end{tabular}

Normally distributed numerical data are presented as mean $\pm \mathrm{SD}$ (unpaired $t$ test). Categorical data are presented as number (\%) ( $\chi^{2}$ test). Non-normally distributed numerical data are presented as median (IQR) (Mann-Whitney U test). dEMG, electromyography of the diaphragm. MIST, minimally invasive surfactant therapy.

\section{Discussion}

This study explores for the first time the effect of exogenous surfactant administration via the MIST procedure on neural breathing effort measured by electrical activity of the diaphragm in preterm infants with RDS. Compared to baseline, the peak and tonic diaphragmatic activity decreased $1 \mathrm{~h}$ after the MIST procedure in the majority of infants, with a trend toward an average reduction of, respectively, 11.8 and $6.3 \%$.

The pulmonary effects of surfactant administration via an endotracheal tube have been extensively studied in animal models and preterm infants with RDS [12-16]. A study in preterm infants showed that MIST improved oxygenation and EELV, similarly to endotracheal administration [7]. Up to now the effect of surfactant administration on neural breathing effort has not been studied either in intubated or in spontaneous breathing preterm infants.
Previous studies have shown that transcutaneous dEMG is able to detect changes in neural breathing effort caused by treatment interventions in preterm infants $[17,18]$.

The decrease in electrical activity of the diaphragm that was seen in the majority of the preterm infants is consistent with our hypothesis. The reduction in peak ${ }_{\mathrm{dEMG}}$ activity is probably best explained by the improved compliance of the respiratory system, which is one of the main variables impacting breathing effort. Improved compliance following surfactant treatment via an endotracheal tube has been reported in previous studies in preterm infants $[16,19]$. The reduction in tonic dEMG $_{\text {activity can be }}$ explained by the increased and more stable EELV after surfactant treatment as reported during both invasive and noninvasive surfactant treatment $[7,13]$. Increased tonic diaphragmatic activity is one of the mechanisms by which preterm infants can increase their EELV in case of surfactant deficiency $[20,21]$. 
An interesting finding was the individual variability in response to MIST, showing that diaphragmatic activity did not decrease in all infants. We can only speculate on the reasons for this. First, the effect of surfactant on compliance of the respiratory system and EELV may vary between infants due to differences in surfactant deposition or surfactant inactivation by alveolar proteins [22]. Second, it could be that the effect of surfactant on compliance of the respiratory system may take longer than the first hour after the procedure as shown in some physiological studies [15, 23]. Finally, the improvement in EELV following MIST might result in relative overdistention of the lung. This would place breathing on the less compliant part of the pressure-volume relationship of the lung as nCPAP pressure was not reduced in the first hour after MIST.

Furthermore, it was interesting to observe an increase in diaphragmatic activity $5 \mathrm{~min}$ after the MIST procedure in the majority of the infants. Again, we can only speculate on possible explanations. First, opening of the mouth during the MIST procedure might reduce the positive airway pressure of the nCPAP. This could lead to a loss of EELV and a decrease in compliance resulting in an increased breathing effort. Second, there might be increased airway resistance due to the surfactant deposition, which will increase the breathing effort. Third, the infants might be still aroused at this time point due to the MIST procedure, which might also affect diaphragmatic activity.

An explorative analysis was done to investigate whether the diaphragmatic response to MIST was influenced by patient and clinical characteristics. The selected characteristics were considered factors that might explain the variability of the response to surfactant administration via MIST on diaphragmatic activity. None of these variables were different between infants who had a decrease in diaphragmatic peak activity and those infants showing an increase. In addition, no difference was seen in $\mathrm{FiO}_{2}$ in the 2 groups of infants. Therefore, the variability of the diaphragmatic response to MIST seems not to influence the clinical response to surfactant administration.

This study has several limitations that need to be addressed. First, this study did not simultaneously measure changes in compliance and resistance of the respiratory system with diaphragmatic activity. Information on these variables would have allowed us to explain some of the findings in our study. However, compliance and resistance of the respiratory system are difficult to measure in infants on noninvasive support. Our findings may be different when administering surfactant prophylactically. Finally, the diaphragmatic activity was only measured up to $1 \mathrm{~h}$ after MIST. It might be that the new balance of the respiratory system after MIST is not yet established in the first hour after surfactant administration and a longer measurement time might change our findings.

In conclusion, this study shows that, in addition to improved oxygenation, the neural breathing effort measured by diaphragmatic activity decreases in the majority of preterm infants in the first hour following surfactant administration via the MIST procedure. However, there is considerable variation in this response, with some infants showing no change or even an increase in neural breathing effort. This explorative study adds important new knowledge on the physiological changes following MIST in preterm infants with RDS. It also provides valuable information for clinicians, i.e., that manifestation of the positive effect of MIST on the respiratory system may take more than $1 \mathrm{~h}$ and is variable between infants. Further research is needed to identify factors that impact the effect of MIST on breathing effort. Such a study would require a large sample size and a longer measurement time. In addition, it would be of interest to compare the effect on neural breathing effort of surfactant administered via an endotracheal tube and MIST.

\section{Disclosure Statement}

The authors declare no conflict of interests and no financial assistance.

\section{Author Contributions}

All of the authors contributed to the conception and design of this study, to collection, analysis, and interpretation of the data, to drafting of this paper for important intellectual content, and to the decision to submit this paper for publication.

References

1 Whitsett JA, Weaver TE: Alveolar development and disease. Am J Respir Cell Mol Biol 2015;53:1-7.

-2 Pickerd N, Kotecha S: Pathophysiology of respiratory distress syndrome. Paediatr Child Health (Oxford) 2009;19:153-157.

-3 Suresh GK, Soll RF: Overview of surfactant replacement trials. J Perinatol 2005;25:S40-S44.

4 Göpel W, Kribs A, Ziegler A, Laux R, Hoehn T, Wieg C, Siegel J, Avenarius S, von der Wense A, Vochem M, Groneck P, Weller U, Möller J, Härtel C, Haller S, Roth B, Herting E; German Neonatal Network: Avoidance of mechanical ventilation by surfactant treatment of spontaneously breathing preterm infants (AMV): an open-label, randomised, controlled trial. Lancet 2011;378:1627-1634.
80 
5 Dargaville PA, Kamlin COF, De Paoli AG, Carlin JB, Orsini F, Soll RF, Davis PG: The OPTIMIST-A trial: evaluation of minimallyinvasive surfactant therapy in preterm infants 25-28 weeks gestation. BMC Pediatr 2014;14: 213.

6 Kanmaz HG, Erdeve O, Canpolat FE, Mutlu B, Dilmen U: Surfactant administration via thin catheter during spontaneous breathing: randomized controlled trial. Pediatrics 2013; 131:e502-e509.

7 Van der Burg PS, de Jongh FH, Miedema M, Frerichs I, van Kaam AH: Effect of minimally invasive surfactant therapy on lung volume and ventilation in preterm infants. J Pediatr 2016;170:67-72.

-8 Kraaijenga JV, Hutten GJ, de Jongh FH, van Kaam AH: Transcutaneous electromyography of the diaphragm: a cardio-respiratory monitor for preterm infants. Pediatr Pulmonol 2014;50:889-895.

9 Guslits BG, Gaston SE, Bryan MH, England SJ, Bryan AC: Diaphragmatic work of breathing in premature human infants. J Appl Physiol 1987;62:1410-1415.

10 O’Brien MJ, van Eykern LA, Oetomo SB, van Vught HA: Transcutaneous respiratory electromyographic monitoring. Crit Care Med 1987;15:294-299.
11 Maarsingh EJ, van Eykern LA, Sprikkelman $\mathrm{AB}$, Hoekstra MO, van Aalderen WM: Respiratory muscle activity measured with a noninvasive EMG technique: technical aspects and reproducibility. J Appl Physiol (1985) 2000;88:1955-1961.

12 Vilstrup C, Gommers D, Bos JA, Lachmann B, Werner O, Larsson A: Natural surfactant instilled in premature lambs increases lung volume and improves ventilation homogeneity within five minutes. Pediatr Res 1992;32: 595-599.

13 Miedema M, de Jongh FH, Frerichs I, van Veenendaal MB, van Kaam AH: Changes in lung volume and ventilation during surfactant treatment in ventilated preterm infants. Am J Respir Crit Care Med 2011;184:100105.

14 Attar MA, Becker MA, Dechert RE, Donn SM: Immediate changes in lung compliance following natural surfactant administration in premature infants with respiratory distress syndrome: a controlled trial. J Perinatol 2004; 24:626-630.

15 Bhutani VK, Abbasi S, Long WA, Gerdes JS: Pulmonary mechanics and energetics in preterm infants who had respiratory distress syndrome treated with synthetic surfactant. J Pediatr 1992;120:S18-S24.

16 Dinger J, Töpfer A, Schaller P, Schwarze R: Functional residual capacity and compliance of the respiratory system after surfactant treatment in premature infants with severe respiratory distress syndrome. Eur J Pediatr 2002;161:485-490.
17 Kraaijenga JV, Hutten GJ, de Jongh FH, van Kaam AH: The effect of caffeine on diaphragmatic activity and tidal volume in preterm infants. J Pediatr 2015;167:70-75.

$\checkmark 18$ Kraaijenga JV, de Waal CG, Hutten GJ, de Jongh FH, van Kaam AH: Diaphragmatic activity during weaning from respiratory support in preterm infants. Arch Dis Child Fetal Neonatal Ed 2017;102:F307-F311.

19 Baraldi E, Pettenazzo A, Filippone M, Magagnin GP, Saia OS, Zachello F: Rapid improvement of static compliance after surfactant therapy in preterm infants with respiratory distress syndrome. Pediatr Pulmonol 1993; 15:157-162.

20 Lopes J, Muller NL, Bryan MH, Bryan AC: Importance of inspiratory muscle tone in maintenance of FRC in the newborn. J Appl Physiol Respir Env Physiol 1981;51:830-834.

21 Stark AR, Cohlan BA, Waggener TB, Frantz ID, Kosch PC: Regulation of end-expiratory lung volume during sleep in premature infants. J Appl Physiol 1987;62:1117-1123.

22 Hallman M, Merritt TA, Bry K: The fate of exogenous surfactant in neonates with respiratory-distress syndrome. Clin Pharmacokinet 1994;26:215-232.

23 Couser RJ, Ferrara TB, Ebert J, Hoekstra RE, Fangman JJ: Effects of exogenous surfactant therapy on dynamic compliance during mechanical breathing in preterm infants with hyaline membrane disease. J Pediatr 1990; 116:119-124. 